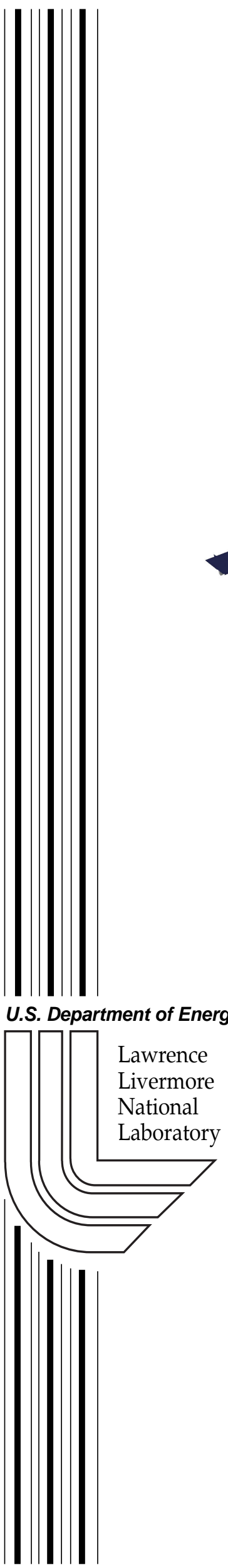

\title{
National Ignition Facility Management Descriptions Revision 9
}

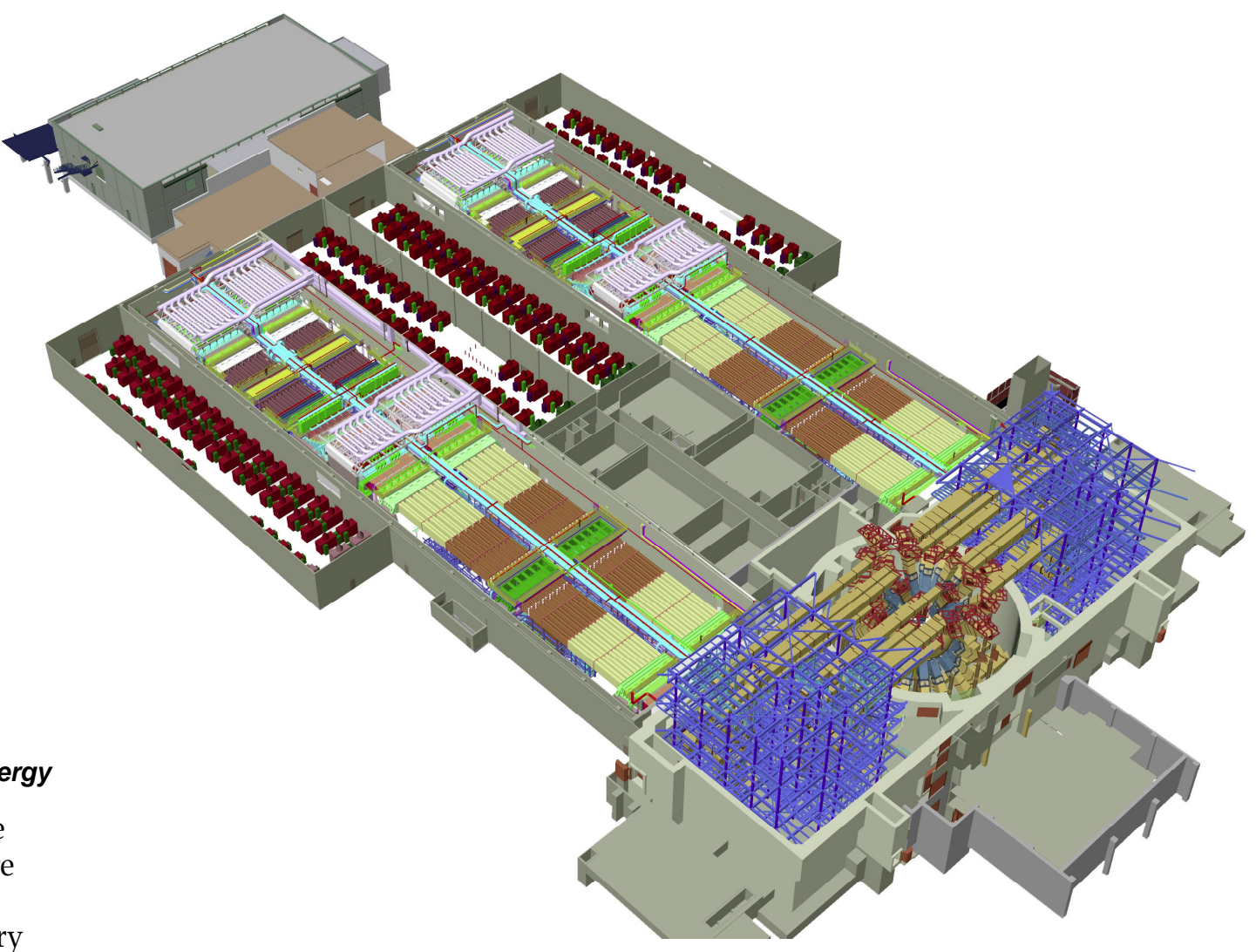

January 2004

Lawrence Livermore

National Laboratory

7000 East Avenue Livermore, CA 94550

Approved for public release; further dissemination unlimited 


\section{DISCLAIMER}

This document was prepared as an account of work sponsored by an agency of the United States Government. Neither the United States Government nor the University of California nor any of their employees, makes any warranty, express or implied, or assumes any legal liability or responsibility for the accuracy, completeness, or usefulness of any information, apparatus, product, or process disclosed, or represents that its use would not infringe privately owned rights. Reference herein to any specific commercial products, process, or service by trade name, trademark, manufacturer, or otherwise, does not necessarily constitute or imply its endorsement, recommendation, or favoring by the United States Government or the University of California. The views and opinions of authors expressed herein do not necessarily state or reflect those of the United States Government or the University of California, and shall not be used for advertising or product endorsement purposes.

This report has been reproduced directly from the best available copy.

Available to DOE and DOE contractors from the

Office of Scientific and Technical Information

P.O. Box 62, Oak Ridge, TN 37831

Prices available from (615) 576-8401, FTS 626-8401

Available to the public from the

National Technical Information Service

U.S. Department of Commerce

5285 Port Royal Rd.,

Springfield, VA 22161

This work was performed under the auspices of the U.S. Department of Energy, National Nuclear Security Administration by University of California Lawrence Livermore National Laboratory under Contract W-7405-Eng-48. 


\section{National Ignition Facility \\ Management Descriptions}

Edward I. Moses

January 2004

LAWRENCE LIVERMORE NATIONAL LABORATORY

University of California $\bullet$ Livermore, California $\bullet 94550$ 


\section{Table of Contents}

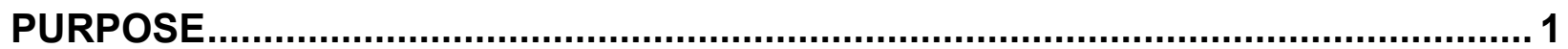

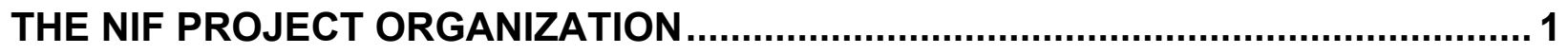

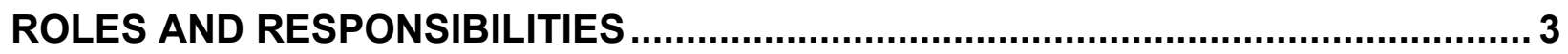

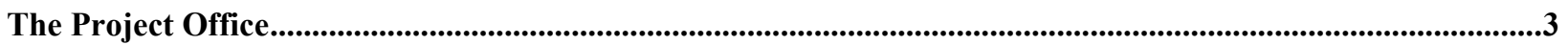

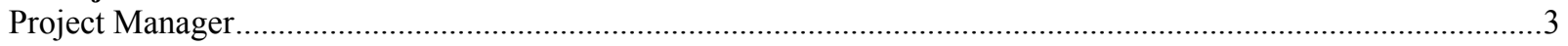

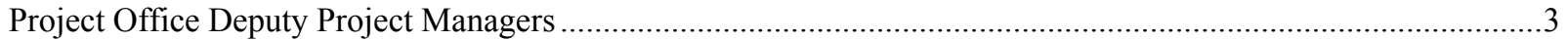

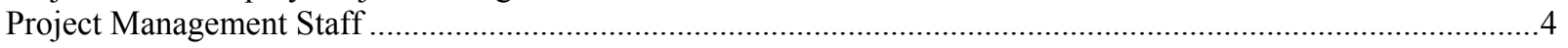

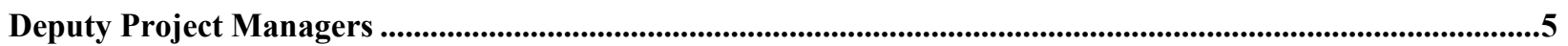

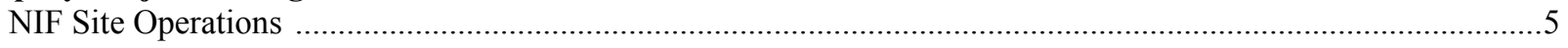

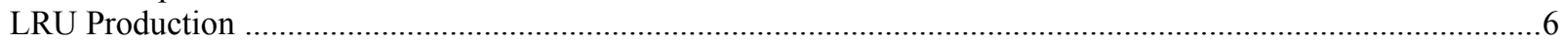

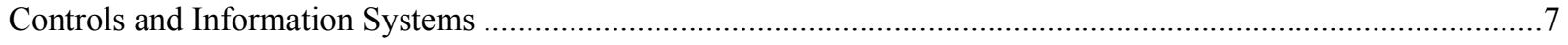

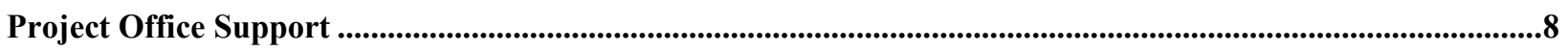

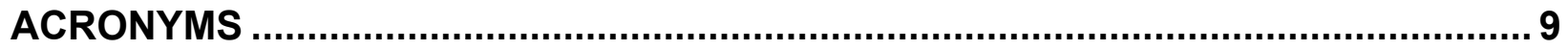




\section{National Ignition Facility Management Descriptions Revision 9}

\section{Purpose}

The purpose of this document is to describe the National Ignition Facility (NIF) Project Organization and the top-level roles and responsibilities of the managers charged with executing the Project.

\section{The NIF Project Organization}

The NIF Project Organization chart is shown in Figure 1. This organization reflects the NIF business model in which the Project Office may be viewed as the funding agency, having overall responsibility for delivering a NIF that meets the approved project technical, cost, schedule and regulatory baseline. The NIF systems, subsystems, and components are supplied by NIF product Deputy Project Managers (DPMs). In this respect, these DPMs and their Associate Project Managers (APMs) function as project contractors who have "cradle to grave" responsibility for their products. The NIF Site Operations Deputy Project Manager (NSO DPM) functions as the plant owner/operator who receives, commissions, and integrates the products into the NIF. As the NIF is assembled and commissioned, Area Integration Managers (AIMs) serve as general integrating contractors. The Systems Engineering/Experimental Physics area maintains responsibility for the ultimate integration of the NIF, from requirements through commissioning operation.

During installation, assembly, verification, and validation test work, the NSO DPM, AIMs, and appropriate APMs provide integrated planning and management oversight of all work in the NIF Facility and on the NIF site. AIMs or Field Area Managers (FAMs) reporting to an AIM, are responsible for oversight and coordination of day-to-day work.

The NSO DPM provides global facility management, including conventional facility services and facility improvements and construction. A Facility Management and Construction APM serves as primary Facility Point of Contact (FPOC).

As the NIF systems are activated, the Commissioning Operations APM is responsible to ensure, through appropriate testing and review, that systems meet their functional, operational, and safety requirements. Further, this APM is responsible for providing the staffing, staff training, and the procedural foundation for NIF operations while operating the NIF during the commissioning phase.

The NIF Project Manager is assisted by additional "at large" Deputy Project Managers, who are assigned specific oversight responsibilities as delineated in this document.

A project office staff provides financial management, assurances, and administrative functions. Within LLNL, the NIF Project resides in the NIF Directorate. The NIF Programs Directorate Office provides personnel management, facilities support, public relations, information technology, umbrella business management, and environmental, safety, and assurances support. 


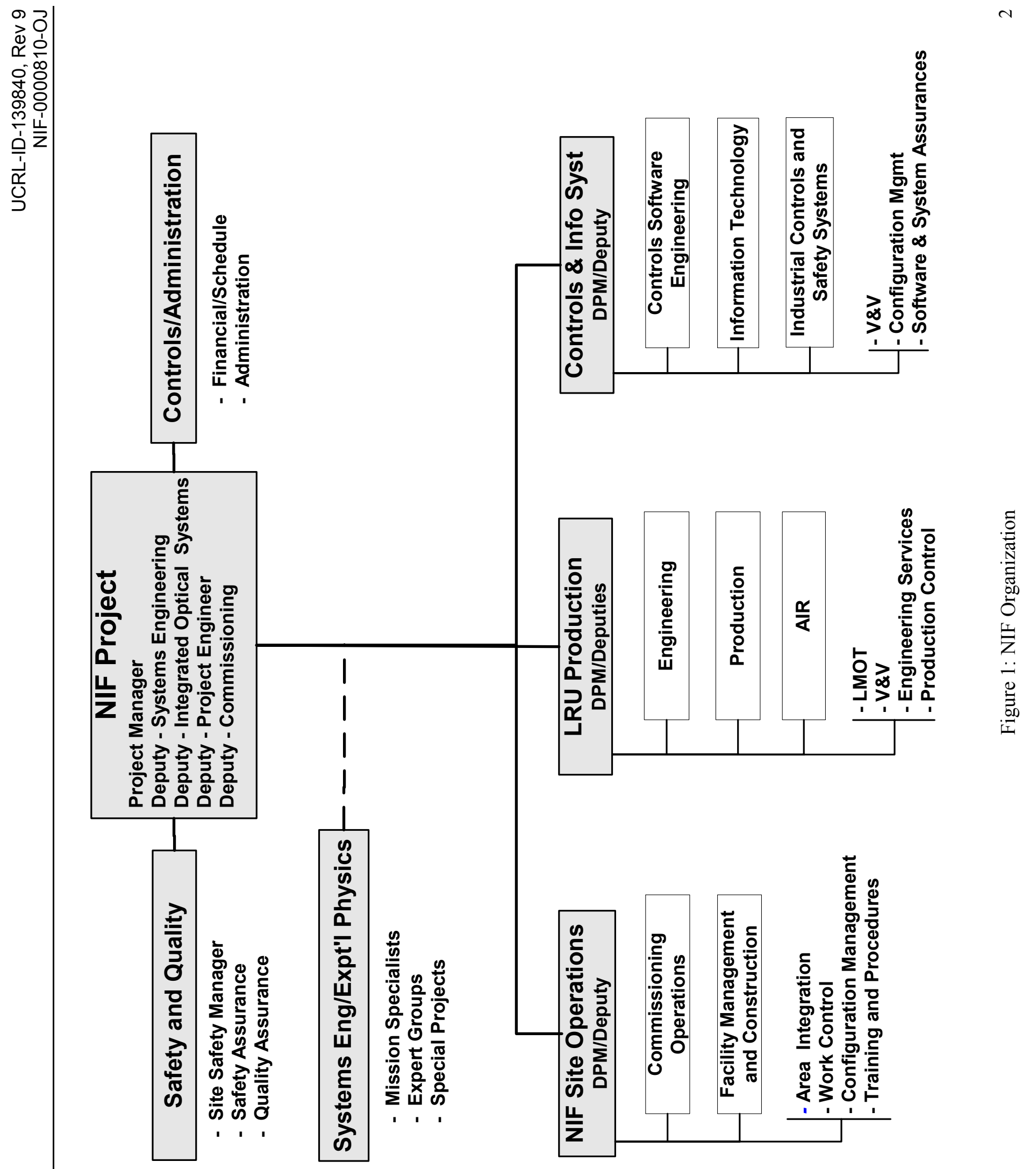




\title{
Roles and Responsibilities
}

\author{
The Project Office
}

\section{Project Manager}

The Project Manager is responsible to execute the Project and direct the participating laboratories and industrial contractors. The Project Manager is responsible to establish, maintain, and control the NIF baseline (technical, cost, and schedule) in accordance with the Project Execution Plan and report status to the National Nuclear Security Administration (NNSA) in a timely manner. Responsibilities include assuring that the Project meets all applicable regulatory requirements and that NIF Project work is conducted under the principles and requirements of the LLNL Integrated Safety Management (ISM) system. In this regard, the NIF Project Manager serves as the Authorizing Individual (AI) for the NIF site, delegating that authority to lower-tier managers as appropriate. The NIF Project Manager reports to the Associate Director of NIF Programs and interfaces with the NNSA Director, Office of the NIF Project, and the Deputy Director/NIF Field Manager.

\section{Deputy Project Managers}

Deputy Project Managers assist the Project Manager in the execution of his duties. The Deputies may be delegated the authority to act for him in his absence. The Project Manager and the Deputies serve as a management team and are involved in all aspects of the management of the Project. As part of the management team, each deputy is delegated specific responsibilities. Four deputies function on an "at large" basis with project-wide oversight responsibilities.

The Deputy Project Manager - Systems Engineering is responsible for technical performance quality assurance, and as such, manages the Systems Engineering organization, including the activities of the senior project scientific staff. The responsibilities of the DPM-Systems Engineering include oversight of technical integration activities across the project, including establishment and flowdown of requirements, interfaces, configuration management, commissioning and operations planning, and system performance. A key function is to establish and conduct a risk identification, evaluation, and mitigation program.

The Deputy Project Manager-Integrated Optical Systems (IOS) is responsible to provide overall integrated leadership for and oversight of all aspects of NIF Project and Program optics and optical systems. As such for the NIF Project, the DPM-IOS maintains close interfaces with Systems Engineering/Experimental Physics and Line Replaceable Unit (LRU) Production and Commissioning Operations. Focus areas include optics development and risk mitigation, performance, engineering, production development, and production and performance verification.

The Deputy Project Manager-Project Engineer is responsible to the NIF Project Manager for providing leadership for and global oversight of the engineering execution aspects of the NIF Project including integration, scope, schedule, cost, risk, communications, and supporting engineering resources. The Project Engineer leads the project's effort to utilize best engineering practices, standards, and tools. The Project Engineer is responsible to provide management focus on and leadership for project activities and areas impacting the achievement of project goals.

The Deputy Project Manager-Commissioning in conjunction with the Commissioning Operations Associate Project Manager provides integration, transition, and verification management from subsystem acceptance tests to a fully commissioned NIF. The Commissioning Manager is focused on verifying that NIF systems meet their functional and operational requirements or that a plan is prepared and approved for the receiving organization to meet these requirements. The Commissioning Manager reports to the NIF Project Manager and is responsible to prepare and oversee the execution of the NIF Commissioning 
Plan, the master plan for commissioning and transitioning to operations of B581/681. With the Quality Assurance (QA) Manager, the Commissioning Manager is responsible to ensure that QA/Quality Control (QC) requirements are defined and met in all commissioning activities.

The functions and responsibilities of the NIF Site Operations, LRU Production and Controls, and Information Systems Deputy Project Managers are described in the Deputy Project Managers section of this document.

\section{Project Management Staff}

The NIF Project Management Team includes Systems Engineering/Experimental Physics and Assurances and Controls/Administration. Assurances and Controls/Administration are described in the Project Office Support section of this document.

The Systems Engineering/Experimental Physics Manager reports to the Project Manager through the Deputy Project Manager-Systems Engineering and is the focal point for systems performance and integration. This responsibility focuses on oversight of the technical integration activities of the project including requirements flow down, technical interface control, risk management, system performance, physical interface control, and commissioning operations planning. Responsibilities include forming and maintaining expert and working groups (e.g., mission support, performance risk analysis, cleanliness, back-reflection, optics performance) to resolve and monitor disposition of key technical issues, integrating NIF experimental science with Commissioning Operations and working closely with the Experimental Planning Advisory Committee (EPAC) to assure the appropriate commissioning utilization of the NIF. When necessary to resolve key technical issues, this manager will define, plan, and manage off-line test and development work to understand and mitigate NIF performance and system/component risks. The Systems Engineering /Experimental Physics Manager supplies knowledgeable, qualified Responsible Individuals (RIs) for Commissioning Operations, such as experimentalists and shot directors. 


\section{Deputy Project Managers}

The Deputy Project Managers (DPMs) are responsible for the scope, schedule, budget, technical, and safety performance for their assigned NIF Work Breakdown Structure (NWBS) elements. NIF Deputy Project Managers are responsible for the NIF site operations or for NIF products. Deputy Project Managers report to the Project Manager, maintaining a significant interface with Systems Engineering/Experimental Physics.

\section{NIF Site Operations Deputy Project Manager}

The NIF Site Operations Deputy Project Manager is the "owner-operator" of the NIF at all stages during commissioning. The NIF Site Operations DPM reports to the NIF Project Manager and is responsible for the day-to-day management of all site activities and for the stewardship of all NIF site assets. The NIF Project Manager has delegated AI responsibilities to the NSO DPM for Integration Work Sheets (IWSs), Operational Safety Procedures (OSPs), and other safety documents associated with NIF operations in B581 and on the NIF site. The NSO DPM is responsible to provide configuration management and site administration, including training, records, databases and visitor control. The NSO leadership staff includes Associate Project Managers (APMs) for Commissioning Operations and Facility Management and Construction. Area Integration Managers, Field Area Managers, and the Work Control Officer are key staff for integration and coordination.

The Commissioning Operations APM, in conjunction with the Deputy Project Manager-Commissioning, provides integration, transition, and verification management from the start of commissioning tests to achieving an operating NIF. The Commissioning Operations Manager is focused on assuring that commissioned systems meet their performance and operational requirements or that there is an approved plan to meet those requirements. The Commissioning Operations APM is responsible for the planning and execution of laser operations in the NIF, including line management responsibility for the operations staff and operations work processes.

The Shot Director, as part of the Commissioning Operations APM's staff, is responsible to lead the Shot Director Team and to conduct laser shots per approved plans and procedures. As such, the Shot Director serves as RI for laser shots. The Shot Director is responsible to: review shot plans, coordinate the activities of shot participants, direct control room operations during shots, and interface with the Integrated Experiment Teams (IETs) and the Beamline Integrated Performance (BLIP) expert group in planning the shots.

The Facility Management and Construction (FM\&C) APM is responsible to serve as the primary NIF Site Facility Point-of-Contact (FPOC) to control access requirements (safety, security, and training) and access to the NIF site. Responsibilities include interfacing with LLNL institutional elements as necessary to support work activities on the site and assuring that the NIF facilities are operated in accordance with the NIF Programs Directorate Integrated Safety Management System Implementation Plan. The Facility Management and Construction APM is responsible to assure that beampath, process, and conventional facilities and utilities are maintained and operated so as to be available to support NIF commissioning operations. The Facility Management and Construction APM is responsible for NIF site construction projects, construction support, site improvements, site indirects and IMI contract closeout. As such, the FM\&C APM works closely with LLNL contracts and procurement, NIF Commissioning Operations, and the AIMs. The FM\&C APM serves as AI for site areas delegated by the NIF Project Manager.

Area Integration Managers (AIMs) lead Area Integration Teams (AITs) that are established for specific NIF geographic areas to manage the integration of all planning and execution activities necessary to 
deliver a commissioned and fully dispositioned system to NIF Commissioning Operations. The AITs include applicable product team leaders, facility representatives, and other designated individuals who may be required to deliver an area's commissioned systems. The AIMs are responsible to ensure that a well-coordinated, unified plan is developed and executed to deliver systems in their assigned area. This includes schedule and cost account plans and work interface agreements. In this regard, an AIM is responsible to ensure that the plan, including detailed product team subplans, represents balanced technical, cost, schedule, and organizational risks. The AIM is alert to identify significant new risks that should be considered by the project's Safety and Performance Review Board. The AIMs serve as the AI for their assigned area when designated to do so by the Project Manager. AIMs may appoint Field Area Managers (FAMs) to oversee and coordinate day-to-day work in their assigned area.

Field Area Managers (FAMs) have the responsibility and authority to coordinate all ongoing work within their assigned area. As such, the FAM is the day-to-day, on-site representative of his/her AIM or operations manager. FAMs report to the AIM or the designated operations manager responsible for their area and are responsible to execute the plans for their area, interface with other FAMs, the Site Manager, the FM\&C APM, and product team leaders to resolve conflicts, interferences, and work priorities. The FAMs are the front-line managers responsible to assure that assigned area activities are planned, hazards evaluated, and effort coordinated through the use of Job Hazards Analysis (JHA) and/or OSP procedures, Safe Plans of Action (SPAs), and other core work procedures.

The Work Control Officer (WCO) manages the NIF Work Control Center that reviews and releases all Work Permits prior to the start of work activities. The Work Control Center is responsible to ensure that NIF work activities are coordinated, reflect Project priorities, and are consistent with system level Lock Out-Tag Out (LOTO) requirements. This includes establishing a system level LOTO configuration. The Work Control Officer is responsible to ensure Quality Control of the ES\&H and work permit processes.

The NIF Site Operations Deputy is also supported by staff responsible for training, procedures and resource management.

\section{NIF LRU Production Deputy Project Manager}

The NIF LRU Production Deputy Project Manager is responsible for the engineering and production of the NIF line replaceable units (LRUs) and their components, and LRU assembly, installation, and refurbishment. The LRU Production Deputy Project Manager also is responsible for advanced optics development-Laser Materials and Optics Technology (LMOT), the verification and validation of product performance, and the engineering supporting services and production control necessary to efficiently deliver these products. Associate Project Managers reporting to the LRU Production Deputy Project Manager are specifically responsible for Engineering, Production, and Assembly, Installation, and Refurbishment. These product APMs serve as the principal RIs for their assigned products at the NIF site. They serve as AIs (e.g., for development and assembly work not covered by the NIF Project Site Safety Program [NPSSP]) when so delegated by the NIF Project Manager.

The Engineering APM is responsible for the scope, schedule, budget, technical, and safety "cradle-tograve" performance of assigned NIF systems, subsystems, and components. Responsibilities include assurance that all engineering work adheres to LLNL engineering and NIF procedures, including engineering development, design work, design reviews, procurement and procurement reviews, configuration management, and verification practices. As a product Associate Project Manager, the Engineering APM maintains responsibility for product requirements flow-down, baseline plan, progress reporting, and interface with the AIMs and Systems Engineering/Experimental Physics. 
The Production APM is responsible for the procurement and production of the NIF equipment. This includes the development and implementation of production strategies, preparation and management of production contracts, and the operation of NIF receiving and storage facilities and the associated production control functions. The Production APM serves as AI for areas delegated by the Project Manager.

The Assembly, Installation, and Refurbishment (AIR) APM is responsible for the assembly, installation, and refurbishment of NIF line replaceable units (LRUs) including large optics processing. These responsibilities include: management and operation of NIF assembly and refurbishment facilities (Optics Assembly Building, Optics Processing Development Laboratory, parts of B391, and the preamplifier module maintenance area), as well as development and implementation of production plans and strategies, staffing plans, training and qualification programs, and the AIR quality program. The AIR APM is responsible for ensuring that AIR facilities and operations, including transportation and handling, are in accordance with all applicable ES\&H and ISM requirements.

The Laser Materials and Optics Technology (LMOT) Manager is responsible for development, facilitization, and production of the NIF large-aperture optics. This includes procurement, process and materials trouble shooting, QC inspection, production tracking and shipping of: (1) laser amplifier glass, (2) lenses and windows, (3) mirrors and polarizers, and (4) KDP (potassium dihydrogen phosphate) and DKDP (deuterated potassium dihydrogen phosphate) crystal plates. Responsibilities include large optics yield improvement and the development of cost effective disposable debris shields.

\section{NIF Controls and Information Systems Deputy Project Manager}

The NIF Control Software and Information Technology (CS\&IT) Deputy Project Manager is responsible for NIF control system software and information technology support for the NIF Project. These responsibilities include software verification and validation along with quality assurance and configuration control. Reporting to the NIF CS\&IT Deputy Project Manager are the APMs for Integrated Computer Control Systems (ICCS) and Information Technology (IT).

The Controls Software Engineering APM is responsible for software engineering, including independent validation and verification, for the NIF integrated computer system and control system elements consisting of supervisory, control system timing, safety interlocks and access controls, target diagnostics controls, and classified systems. These responsibilities include software configuration control and quality assurance.

The Industrial Controls and Safety Systems APM is responsible for the design, procurement, installation and verification testing of the NIF safety interlock system (SIS), transportation and handling controls, NIF industrial controls, and the NIF facility security control infrastructure.

The NIF Programs Information and Technology Leader supports the NIF Project directly as the Information Technology APM in the areas of application development and project support systems, including engineering support, data archiving, and network and server infrastructure. Specific project infrastructure applications supported include Glovia, LoCoS, NPS, RMS, MDMS, PICS, NIF Data, and CAD applications. Responsibilities include IT configuration control and quality assurance. 


\section{Project Office Support}

The Project Control Manager reports to the Project Manager and is responsible for the project cost and schedule baseline and financial tracking and reporting against that baseline. This responsibility includes coordinating and integrating the cost and schedule baselines and the related core documents, including Baseline Change Proposals, Project Data Sheets, Control Account Plans, the Project Execution Plan, and the Project Master Schedule. The Project Control Manager interfaces with the NIF Program Business Manager for Project budget, cost reporting and financial planning, control processes, and systems.

The NIF Program Safety Manager supports the NIF Project as the NIF Site Safety Manager as part of his/her overall NIF program responsibilities. The NIF Program Safety Manager, working closely with line management in the NIF Program Directorate, is responsible to lead the NIF Program Safety Team, working to maximize their effectiveness in supporting line management's commitment to safety. This includes providing uniform, consistent, timely guidance on interpretation and implementation of rules, codes and standards. The NIF Program Safety Manager assists line management in development, implementation and assessment of work control processes especially as they pertain to Safety. This position is the NIF Program Directorate's single point of contact and interface to NIF Program Assurances and the Laboratory on all aspects of NIF Program safety. The responsibilities also include NIF Program safety monitoring and review and assisting line management in auditing NIF Program safety performance.

The Safety Assurance Manager is responsible for the environmental, safety, health, and security plans and evaluations for the NIF Project. This responsibility includes preparing and ensuring implementation of the ES\&H Management Plan and the NPSSP, developing the NIF ALARA (as low as reasonably achievable) Program, Security Plan, ES\&H Risk Management Plan, and with the Associate Project Manager for Commissioning Operations, Operational Safety Requirements (OSRs). The Safety Assurance Manager is responsible for NIF National Environmental Policy Act (NEPA) policies, documentation, permits and actions, and providing monitoring to assure that all applicable federal, state, local, and LLNL ES\&H regulations are followed.

The Quality Assurance Manager, reporting to the Project Manager, is responsible for planning, implementing, and auditing QA/QC activities for the Project in conformance with best practices and applicable NNSA and LLNL requirements. The Quality Assurance Manager is responsible for the NIF Project QA Program Plan and its implementing procedures along with developing and documenting quality-level criteria to implement graded quality assurance. The Quality Assurance Manager is responsible to verify the quality of Project and contractor work by audit and independent Management Review.

The Project Administrator provides administrative functions and assistance in support of the Project and provides supervision of the Project administrative staff. He/she coordinates assignments for ongoing tasks of mutual benefit and assists in the dissemination of information on Project activities. The Project Administrator is responsible to coordinate the Project's appraisal, ranking, and salary management process, manage and coordinate the personnel recruiting functions, and to coordinate and facilitate Project administrative functions (e.g., training, security, document control, correspondence, classified document accountability, affirmative action, supplemental labor, and workforce and space planning). 


\section{Acronyms}

AI

AIM

AIR

AIT

ALARA

APM

BLIP

CAD

CS\&IT

DKDP

DOE

DPM

EFC

EPAC

ES\&H

FAM

FM\&C

FPOC

HED

ICCS

ICF

IET

IOS

ISM

IT

IWS

JHA

KDP

LES

LMOT

LoCoS

LOTO

LRU

MDMS

NEPA

NIF

NNSA

NPS

NPSSP

NSO

NWBS

OSP

OSR

PICS

QA

QC

RI

RMS

SIS

SPA

WCO
Authorizing Individual

Area Integration Manager

Assembly, Installation, and Refurbishment

Area Integration Team

As Low As Reasonably Achievable

Associate Project Manager

Beam Line Integrated Performance

computer-aided design

Control Software and Information Technology

dueterated potassium dihydrogen phosphate

Department of Energy

Deputy Project Manager

Experimental Facilities Commissioning

Experimental Planning Advisory Committee

Environment, Safety and Health

Field Area Manager

Facility Management and Construction

Facility Point of Contact

High Energy Density

Integrated Computer Control System

Inertial Confinement Fusion

Integrated Expert Teams

Integrated Optical Systems

Integrated Safety Management

Information Technology

Integration Work Sheet

Job Hazard Analysis

potassium dihydrogen phosphate

Laser Experimental Systems

Laser Materials and Optics Technology

Location Component and State (tracking system)

Lockout/Tagout

Line Replaceable Unit

Metrology Data Management System

National Environmental Policy Act

National Ignition Facility

National Nuclear Security Administration

NIF Planning System

NIF Project Site Safety Plan

NIF Site Operations

NIF Work Breakdown Structure

Operational Safety Procedure

Operational Safety Requirements

Problem Identification and Correction System

Quality Assurance

Quality Control

Responsible Individual

Requirements Management System

Safety Interlock System

Safe Plan of Action

Work Control Officer 